\title{
The health promoting conversations intervention for families with a critically ill relative: A pilot study
}

Susanna Ågren, Anna Eriksson, Mats Fredrikson, Gunilla Hollman Frisman and Lotti Orwelius

The self-archived postprint version of this journal article is available at Linköping University Institutional Repository (DiVA):

http:/ / urn.kb.se/ resolve?urn=urn:nbn:se:liu:diva- 153642

N.B.: When citing this work, cite the original publication.

Agren, S., Eriksson, A., Fredrikson, M., Hollman Frisman, G., Orwelius, L., (2019), The health promoting conversations intervention for families with a critically ill relative: A pilot study, Intensive \& Critical Care Nursing, 50, 103-110. https:// doi.org/ 10.1016/j.iccn.2018.04.007

Original publication available at:

https:// doi.org/ 10.1016/j.iccn.2018.04.007

Copyright: Elsevier (12 months)

http:// www.elsevier.com/

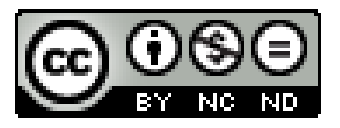


The Health Promoting Conversations intervention for families with a critically ill relative: a pilot $\mathrm{RCT}$

Ågren S, CCRN PhD ${ }^{1}$; Eriksson A. CCRN ${ }^{2}$; Fredrikson M, Ass. professor $\mathrm{PhD}^{3}$; HollmanFrisman G. $\mathrm{PhD}^{4}$; Orwelius L. CCRN, $\mathrm{PhD}^{5}$

${ }^{1}$ Department of Cardiothoracic Surgery and Department of Medical and Health Sciences Linköping University, Sweden. Susanna.Agren@liu.se

${ }^{2}$ Department of Intensive Care, Linköping University, County Council of Östergötland, Linköping, Sweden. Anna.J.Eriksson@regionostergotland.se

${ }^{3}$ Division of Occupational and Environmental Medicine, Department of Clinical and Experimental Medicine and Forum Östergötland, Linköping University, Linköping, Sweden. Mats.fredrikson@liu.se

${ }^{4}$ Anesthetics, Operations and Speciality Surgery Center and Department of Medical and Health Sciences, Linköping University, 58185 Linköping, Sweden.

Gunilla.Hollman.Frisman@liu.se.

${ }^{5}$ Department of Intensive Care, Clinical and Experimental Medicine, Linköping University, County Council of Östergötland, Linköping, Sweden. Lotti.Orvelius@regionostergotland.se

Corresponding author: Susanna Ågren, Department of Cardiothoracic Surgery and Department of Medical and Health Sciences Linköping University, Sweden, 58185 Linköping, Sweden. E-mail: Susanna.Agren@liu.se Phone: +46 732702411

\section{Acknowledgements}

The authors thank the families who participated in this study and gratefully acknowledge the help of Ingrid Wåhlin of Kalmar Hospital and her co-workers at the intensive care unit at Kalmar Hospital.

Role of the funding source: The present study is supported, in part, by a grant from the Health Research Council in the South-East of Sweden (FORSS 466311).

Conflict of interest: The authors have no conflicts of interest to disclose.

Clinical Trial registration number: NCT03325049 


\section{relative: a pilot $\mathrm{RCT}$}

\section{Summary}

Background: After intensive care unit treatment, patients often have prolonged impairments that affect their physical, cognitive, and mental health. Family members can face overwhelming and emotionally challenging situations, and their concerns and needs must be addressed.

Objective: We investigated the outcomes of a pilot randomised control trial nurse-led family intervention, Health Promoting Conversations, which focused on family functioning and wellbeing in families with a critically ill member.

Study design: This randomised controlled pilot study used a pre-test, post-test design with intervention and control groups to investigate the outcomes of the nurse-led intervention in 17 families.

Outcome measures: The Health Promoting Conversations intervention was evaluated using validated instruments that measure family functioning and family wellbeing: the General Functioning sub-scale from the McMaster Family Assessment Device; the Family Sense of Coherence, the Herth Hope Index, and the Medical Outcome Short-Form Health Survey. Descriptive and analytical statistical methods were used to analyse the data.

Results: After 12 months, the intervention group reported better family functioning than the control group. The intervention group also had better social functioning and mental health after 12 months.

Conclusion: This intervention may improve family wellbeing by improving family function, reducing stress, and promoting better mental health.

Keywords: family conversations; family function; ICU; intervention; support; wellbeing. 


\section{Word count:}

\section{Introduction}

3 Viewing the family as a unit (patient and family members together) of research and care is

4 still very rare in Swedish health care. Therefore, there is a lack of quantitative, evidencebased, family-centred interventions, such as the use of health-promoting family conversations, as supportive nursing actions for families with a critically ill member. Family health conversations between nurses and families are of utmost importance to create a trusting caring relationship and enhance family health after intensive care (Benzien et al.

9 2008).

Every year, millions of people worldwide are discharged from intensive care units (ICUs) after a critical illness and continue their rehabilitation in hospital wards and at home (Iwashyna, 2010). Many ICU survivors have prolonged impairments that affect their physical, cognitive, and mental health. Because of the physical and emotional stress experienced during their critical illness and ICU hospitalisation, up to $20 \%$ are at risk of developing post-traumatic stress disorder (PTSD) (Davydow et al., 2008). Among the patient's family members, the prevalence of PTSD may be even higher (up to 57\%) (Beusekom et al., 2016). Along with PTSD, family members may also experience symptoms of depression and anxiety, a syndrome called post-intensive care syndrome (PICS family) (Jensen et al., 2015; van Beusekom et al., 2016). Other factors that increase the risk of PICS family include condition severity, patient age and sex, whether the patient is treated with a ventilator, the severity of the illness, and previous anxiety in the family (Jensen et al., 2015; van Beusekom et al., 2016, Köse et al. 2016). A recent study found that these symptoms in family members persisted 3 months after ICU discharge while they decreased in patients (Fumis 2015). PICS family, should therefore be assessed in the family members of patients who survive ICU treatment (Probst et al. 2016). 
1 ICU patients' family members are prone to shame feelings, especially when having low

2 levels of education and living with the patient (Koulouras et al. 2017). Family members face overwhelming and emotionally challenging situations, and their concerns and needs must be addressed (Linnarsson et al., 2010). The family is important in terms of patient recovery; accordingly, health professionals should address the family’s contributions to recovery to help prevent or improve the patient's post-ICU symptoms (Ågård et al., 2015). There is little evidence from RCTs regarding family support, although some studies have looked at patient diaries to assess psychological recovery after critical illness and to assess the contributions of family members to recovery. Studies reported that post-traumatic stress symptoms were reduced in the family members of patients recovering from ICU treatment who received patient diaries (Ullman et al., 2015, Parker et al. 2015).

A review article reports on Patient, Family-Centred Care (PFCC), an internationally advocated as a way to improve patient care. Research into PFCC interventions is diverse; however, few researchers present a multi-dimensional approach incorporating a culture shift to enact PFCC throughout the ICU trajectory (Mitchell et aal. 2016). The foundation of family-focused nursing theory is based on the Family Assessment and Intervention model (Wright \& Leahey 2009) and the Illness Belief Model (Wright \& Bell 2009, Wright, Watson \& Bell 2002) developed at the Family Nursing Unit, Calgary University, Canada. The models are based on systems theory, cybernetics, communication theory, and change theory. The Swedish model for family-focused nursing, influenced by the Calgary models, was developed in Kalmar by Benzein et al (2008). The theoretical foundation was based on salutogenetic and constructivist approaches. A model for communication between nurses and families, known as the Health-Promoting Family Conversation model, was derived from these theories.

Essential elements of this model include viewing the world as multiversity (Maturana 1988) and using reflection as a way to change beliefs (Anderson 2003). The relationship between 
1 the nurse and family is non-hierarchical, where communication is built on partnership. Both

2 the nurse and the family contribute with their resources and knowledge; thus, meetings are

3 characterised by mutual learning (Benzein et al. 2008).

4 However, to our knowledge, the Health Promoting Conversations intervention has not been

5 used in the context of ICU patients and their families. Furthermore, despite the mounting

6 interest of Sweden and the Nordic countries in working with families from the perspective of

7 family systems nursing (Flanagan, 2001), clinical interventions used in the family paradigm

8 are often supported theoretically rather than empirically (Harmon Hanson et al., 2005;

9 Östlund, 2010; Wright \& Leahey, 2013). More experimental designs are needed to strengthen

10 the evidence base of family nursing interventions, especially studies that produce empirical

11 evidence (Östlund \& Persson 2014). The present study aimed to fill some of these knowledge gaps by providing evidence of the effectiveness and clinical relevance of the Health Promoting Conversations intervention.

\section{Objective}

The objective was to investigate outcomes of a pilot randomised control trial (RCT), nurseled Health Promoting Conversations intervention. This intervention was conducted with families and focussed on family functioning and wellbeing in families with a member who was formerly critically ill.

\section{Methods}

\section{Study design}

The study design was a pilot RCT with the intervention group undergoing the Health Promoting Conversations and the control group receiving usual care. 


\section{Setting}

2 This pilot RCT study with identical interventions was performed in two intensive care units

\section{Sample/Participants}

7 The study included 17 families recruited consecutively, seven in the intervention group and ten in the control group. The inclusion criteria were as follows: patient age $>18$ years; patient treated in the ICU for at least 72 hours and alive; at least one family member (age $>15$ years) interested in participating. Nurses at the intensive care unit asked the patient if he or she and some of the family members were interested in participating in the study. The families who showed an interest were then contacted by the nurses (AE, IW) to obtain oral and written content.

Three weeks after each patient was discharged from the ICU, the nurse responsible for the Health Promoting Conversation intervention sent written information by mail about the study and then made a phone call to the patient to ask if he or she was interested in participating in the study. If a family member agreed to participate, the patient identified other family members, and they were also asked to participate. Both the patients and the family members had to understand Swedish and be able to sign an informed consent form. Before randomisation, the participants filled out baseline questionnaires. Families that chosed to participate were randomised to either the control or intervention group. The randomisation was performed by the statistician using the "Ralloc" procedure in Stata with blocks of 4. 1) the intervention group received traditional care with follow-up visits and a health-promoting conversation with their families; and 2) the control group received traditional care with follow-up visits. The interventions took place at the hospital in connection with a follow-up 
1 visit. Follow-up vistit were always conducted in a private room with only the patient, family

2 and nurses present.

\section{The Health Promoting Conversations intervention}

5 The patient and family members first discussed the aim of the intervention. The aim of the

6 Health Promoting Conversations intervention is to create a context for change that was

7 related to each family's identified problems and resources. The discussion also provided

8 framework for the conversation series and discussed the expectations of the family and the

9 nurses regarding the conversations and each other's roles. All family members were invited

to tell their own stories and to listen to each other's stories about how they were experiencing the current situation. The conversation sessions focused on topics that each family considered important, and the dialogue and questions aimed to identify and make use of the resources available within and outside the family (Wright \& Leahey, 2009).

In the intervention group, there were three health-promoting conversations with each family after the discharge. The health-promoting conversations were held within an approximately 4- to 8-week period with an interval of 2 weeks between conversations. The first conversation lasted approximately 2 hours, and the two follow-up conversations lasted approximately 3040 minutes. One or two research nurses who were not involved in the care of the patients had the conversations with the families. The nurses took responsibility for the conversations by, for example, asking reflecting questions.

At the end of each conversation, the nurses gave the family the chance to listen to a short reflection by the nurses summarising what they and the families had talked about. A closing letter was sent 2 to 3 weeks after the final conversation that summarised all of the conversations and provided further opportunities for reflection. To standardise the intervention, all participating research nurses completed formal theoretical education and 
1 practical training related to the Health Promoting Conversations intervention at the School of

2 Health and Caring Sciences, Linnaeus University, Kalmar, Sweden. All conversations were

3 recorded, and adherence to the intervention was constantly evaluated.

\section{The control group}

5 The patients and the partners in the control group received standard care, and nothing

6 changed regarding treatment and follow-up during the time of the study. Standard care is

7 addressed to the patient and concentrates on the patient's treatment and needs, including

8 patient follow-up according to national guidelines. Although family members could follow

9 the patients to hospital appointments, they were not systematically invited to participate

10 during the visits.

\section{Data collection}

Demographic self-reported data were collected during 2013- 2015 from the families.

Additional baseline data were collected to assess family functioning and wellbeing in the intervention group and the control group 1-2 months after the critical illness and before the start of the intervention. Follow-up assessments were conducted 3 and 12 months after the critical illness for both groups. Additionally, background data, including health history, were collected using a self-administered questionnaire that asked about age; sex; education level; habits like smoking, alcohol consumption, and physical activity; psychosocial support; comorbidity; and risk of mortality (Charlson et al., 1987).

Based on a power calculation for this study using an unpaired t-test for a larger study, at least 100 patients and family members were needed (50 in the intervention group and 50 in the control group) for the study. The calculation was based on a medium effect size $(\mathrm{ES}=0.6, \alpha$ $=0: 05 ; 1-\beta=0.8$ ). This pilot study was conducted to determine whether a larger study is merited, and this study included 17 families. 
2 The primary outcome variables in this study were family functioning and the secondary outcome variables were family wellbeing. The following instruments were used in this study: 1) General Functioning (GF) sub-scale from the McMaster Family Assessment Device (FAD); 2) Family Sense of Coherence (F-SOC/F-KASAM); 3) Herth Hope Index (HHI); and 4) Medical Outcome Short-Form health survey (SF-36).

7

\section{Family functioning}

Family functioning was assessed with the GF sub-scale from the FAD (Epstein et al., Baldwin, \& Bishop, 1983). The FAD is a 60-item self-reported questionnaire developed to assess family functioning within 7 dimensions (Alderfer et al., 2008), FAD was considered to have a very large evidence base and is one of the most well established family scales. This study only used the general functioning sub-scale (GF) since this sub-scale summarises family functioning well and has been recommended instead of the 60-item FAD (Ridenour et al., 1999). The GF is a 12-item scale designed to measure self-reported perceived overall family functioning (Wright and Leahey, 2009, 2013). Each item is rated on a four-point Likert scale: 'strongly agree' $=1$, 'agree' $=2$, 'disagree' $=3$ and 'strongly disagree' $=4$. The scale scores ranges from 12 to 48, with lower scores indicating better family functioning. The GF was translated into Swedish and has been pilot tested in Swedish samples, and the scale has shown satisfactory reliability and acceptable validity of 0.90 (Bylund et al., 2015). The reliability coefficient Cronbach's alpha was 0.86 (95\% CI 0.72-0.94) $p<0.001$, in this study.

Family wellbeing was assessed with two instruments, F-SOC/F-KASAM and HHI. 
1 F-SOC/F-KASAM/stress measures the perceived consequences of family life and successful

2 management of family stress associated with family coherence. It has 3 dimensions,

3

4

5

6 comprehensibility, manageability, and meaningfulness (Antonovsky and Sourani, 1988, Eriksson, Lindström 2005), which have all been theoretically and empirically linked to wellbeing. The questionnaire consists of 12 statements with Likert-type responses that are rated on a 7-point scale. The scale scores range from 12 to 84, with higher scores indicating a greater sense of coherence. The F-SOC has sound psychometric properties (Sagy and Dotan, 2001). The scale was recently translated into Swedish and was pilot-tested (Möllerberg, in process.) The reliability coefficient Cronbach’s alpha was 0.91 (95\% CI 0.81-0.96) $p<0.001$, in this study.

The Herth Hope Index (HHI) was developed for use in advanced cancer patients (Herth, 1992) and is based on a model developed by Dufault and Martocchio (1985). The instrument was translated into Swedish (HHI-S) and has been validated in a Swedish palliative population that included patients and their family members (Benzein and Berg, 2003). The instrument consists of 12 items scored on a Likert-type scale that ranges from 1 to 4 , where 1 represents ‘strongly disagree' and 4 'strongly agree'. The total minimum score is 12 , and the maximum score is 48. A higher score indicates a higher level of hope (Benzein and Berg, 2003; Herth, 1992). The reliability coefficient Cronbach’s alpha was 0.61 (95\% CI 0.21-0.82) $p=0.004$, in this study.

\section{Health-related quality of life}

The SF-36 instrument was chosen for the evaluation of health-related quality of life (HRQoL). This instrument has been translated into Swedish and was validated in a representative sample of the population (Sullivan, 1995). The SF-36 is a generic 36-item 
1 scale that evaluates HRQoL in 8 dimensions. The dimensions are weighed together in two

2 consecutive indexes, a physical component score (PCS) and a mental component score

3 (MCS). The physical index is made up of 4 dimensions: physical functioning, physical role

4 functioning, bodily pain, and general health, The mental index also consists of 4 dimensions:

5 vitality, social functioning, emotional role functioning, and mental health. The scores on all

6 sub-scales are transformed to a scale from 0 to 100, where a higher score indicates better

7 perceived health. The SF-36 is a well-established and frequently used instrument and has

8 good reliability and validity (Ware, 1992). Most reliability estimates have exceeded the 0.80

9 level (Ware, 1993). The reliability coefficient Cronbach’s alpha was 0.93 (95\% CI 0.87-0.97)

$10 \quad p<0.001$, in this study.

\section{Data analysis}

Both descriptive and analytical statistical methods were used to analyse the data. Univariate methods were used to describe the sample. For comparisons of background variables between the intervention and control groups, the independent t-test, one-way ANOVA, repeated measures ANOVA, and chi $^{2}$-tests were used. The Charlson Comorbidity Index Mixed model regression analysis was used to evaluate the hypothesised effects of the intervention. The level for statistical significance was set at $\mathrm{p}<0.05$. Stata MP version 14.1 (StataCorp LLC, College Station, USA). A statistician was involved in the data analysis (MF).

\section{Ethical considerations}

This study conformed to the principles outlined in the Declaration of Helsinki (WMA 2013). Permission to perform the study was obtained from the Regional Ethics Review Board in Linköping, Sweden (Dnr 2013/228-31). The patients and their families were approached in a sensitive manner and were given verbal and written information about the study. They 
1 provided written informed consent prior to their participation. Participants were informed

2 during each conversation that they could withdraw from the study at any time without any

\section{Results}

9

effects on any future treatment and care. In addition, the participants were told that they could meet with a social worker if they wished, but the situation did not arise during the intervention. All recorded personal data and identifiable information were considered to be confidential and were stored securely.

A total of 17 families with 45 family members were included in the pilot study at baseline and completed the demographic assessment (Figure 1). Three families with 15 family members did not complete the assessment at the 3-month time point, and an additional four families with eight members did not complete the assessment at the 12-month follow up. One patient was not alive after 12 months (report raw data 65\% in the intervention group and 40\% in the control group). We didn’t ask the families the reason for this due to ethical reasons, but it was likely because of sickness and fatigue. Table 1 shows the clinical and demographic characteristics of the patients and families. Nearly $50 \%$ of the patients were female, and the majority of the family members were partners. "Not working” was dominant in individuals in both the control and intervention groups. Length of ICU stay for the control group was 8 days and for the intervention group 7 days.

\section{Family functioning - primary outcome}

Intervention families experienced a statistically significant improvement in family functioning (GF) from baseline to 12 months ( $p=0.03$; Table 2). The intervention families showed a statistically significantly increased family functioning (GF) from baseline to 3 
1 months compared with the control group ( $p=0.005$; Appendix 1). The difference disappeared

2 at 12 months.

\section{Family wellbeing - secondary outcome}

$4 \quad$ Family wellbeing, as measured by KASAM/stress, showed decreased stress in the

5 intervention group after 3 months but not after 12 months compared with the control group.

6 Hope (HHI) did not show greater improvement after 3 or 12 months in the intervention group

7 compared with the control group. There were no significant differences between the groups

8 (Figure 2).

9

\section{Health-related quality of life}

There was statistically significant increase in how the intervention families perceived two of the eight dimensions of the SF-36, namely social functioning (SF) $(p=0.02)$ and mental health (MH) $(p=0.01)$ from baseline to 12 months (Table 2). Although not statistically significant, an increase of 5 points or more was seen from baseline to 12 months in all eight dimensions for the intervention group and in four dimensions for the control group (GH, VT, SF, and RE), indicating clinically important improvement. We defined a clinical improvemnet in accordance with the developer of the instrument, i.e. an increase of 5 points or more (Ware, 2001; Dowdy, 2005). For the mental component score (MCS), the intervention group significantly increased over time compared with the control group ( $p=0.04$ ), increasing $>5$ points between baseline and 3 months. No changes were seen in the intervention group over time.

\section{Patients vs. family members}

When the results for patients in the intervention and control groups were analysed, the results were similar to those found for the groups as a whole (i.e. for patients plus family members in 
1 each group). The one exception was the HHI. For this instrument, hope was improved among

2 the patients between baseline and 3 and 12 months when their data were analysed separately

3 (data not shown; see Appendix 2). There were no significant differences.

4

\section{Discussion}

6 The present study evaluated the Health Promoting Conversations intervention (Benzein, 7 Hagberg, \& Saveman, 2008; Wright \& Leahey, 2009), which was previously found to

8 improve the health and wellbeing of patients in palliative care who were dealing with chronic

9 illness (Benzein \& Saveman, 2008; Benzein et al., 2015; Dorell et al., 2017). The new and important findings from this study are that the Health Promoting Conversations intervention improved family function over time, strengthened family wellbeing regarding stress in the short-term, and increased perceived HRQoL in terms of social functioning and mental health over time in family members of formerly critically ill patients. However, the Health Promoting Conversations intervention did not significantly affect short- or long-term family wellbeing regarding hope.

This is to our knowledge the first study to evaluate the effect of health promoting conversations of critical ilness. Health-promoting conversations can benefit the entire family, not only the patient. This will prevent family ill-health and promote family functioning and well-being.

The level of stress decreased for the intervention group compared with the control group after the Health Promoting Conversations intervention. Changes in family roles or responsibilities and feelings of stress can be caused by, for example, being close to the patient and being out of work. This can create a constant state of uncertainty about future life related to critical illness may also cause stress (Frivold et al., 2016; Eggenberger and Nelms, 2007). 
1 The intervention group had better family functioning from baseline to 12 months and a trend

2 was seen that the stress level worsened over time for the control group. Healthy family

3 functioning can support familes and help them adhere to the situation. Moreover, healthy

4 family relationships help support patients’ physical and emotional health and that of the

5 family as a unit (Bylund et al., 2015, Svenningsen et al. 2017).

6 The families that got the Health Promoting Conversations intervention perceived that their

7 HRQoL improved significant over time in terms of social functioning and mental health, and

85 scores in each eight dimensions indicated clinical improvement (Ware, 2001; Dowdy,

9 2005). It was a difference between baseline and 3 months, i.e. after the first Health Promoting

10 Conversation, and a follow-up visit at 12 months showed that this increase was maintained.

11 Regarding the control group, we assume that follow-up visits could have positive effects on the families' mental health as well as promote even physical health. The summary component PCS and MCS increased over time for both the intervention and control groups, although these increases were only statistically significant for the MCS. Tilburgs et al (2015) shows that it is possible to positively influence the QOL after an ICU admission by providing social support from family and friends (Tilburgs, 2015). The control group who got traditional follow-up visit at 3 months showed a trend to increase the level of hope. Family members having hope and hopefulness get positive energy and strength supporting the patient’s wellbeing (Wåhlin, 2006). Hopelessness is an independent risk factor for mortality for previously critically ill patients (Orwelius, 2017); accordingly, support from family members is very important for the patient and has a significant impact on the patient's HRQoL (Tilburgs, 2015). In addition, in population-based studies and in other patient groups, hopelessness after critical illness is an independent predictor of risk of somatic disease and death (Garvin, 2009; Everson, 2000). 
1 Another intervention study offered group communications for the partners of former ICU

2 patients. Group communications contributed to a feeling of togetherness and confirmation.

3 Sharing experiences with others in a similar situation is one way for partners to be able to

4 move on in life

5 (Ahlberg et al., 2015). Interventions based on focus groups or technology has been

6 developed aiming at providing family support regading information needs as well as coping

7 strategies (Kirshbaum-Moriah et al. 2016, Chiang et al. 2017).

8 To our knowledge, this is the first study to examine whether a Health Promoting

9 Conversation intervention will be valuable for patients who have been critically ill and for

10 their families in terms of improving family functioning and wellbeing. However, larger

11 studies are needed to support results from this pilot study.

\section{Limitations}

The results in this study are preliminary, the study was rather small and a limitation is also that we do not have equal groups. However, this was a pilot study, and the positive results suggest that a larger study is warranted. Notably, however, the HHI scale showed a reliability coefficient of 0.61 , which may indicate that the conclusions should be carefully considered (Benzein, Berg et al. (2003). In addition, 65\% of the intervention families members and only $40 \%$ of the controls completed the study at 12 months and may be related to fatigue and sickness of the patient and family members.

\section{Conclusion}

Health promoting conversations may improve family wellbeing by improving family function, reducing stress, and promoting better mental health. This study will add to clinical practice to support families affected by illness, whose support needs have often been 
1 unrecognised and unsupported. Health promoting conversations will contribute to an

2 evidence-based change of practice in the care of people with critical illness and their family

3 members.

4 Implications for Clinical practice

5

6

7

- Within the frame of "Health promoting conversations", nurses have opportunities to mitigate suffering and to find relationship, space and language that work in synergy with families to support them in identifying own strengths and resources, learning and finding new strategies for managing their daily life.

- Excellent family nursing allows possibilities for the illness experience to become approachable and manageable in ways that respect the contextualized experience of those who are ill and their families.

- This will prevent family ill-health and promote family functioning and well-being.

- This study will therefore add to clinical practice to support families affected by illness, whose support needs have often been unrecognised and unsupported.

\section{Acknowledgements}

The authors thank the families who participated in this study and gratefully acknowledge the help of Ingrid Wåhlin and her co-workers at the intensive care unit at Kalmar Hospital, Sweden.

Role of the funding source: The present study is supported, by a grant from the Health Research Council in the South-East of Sweden (FORSS 466311) and Department of Anaesthesiology and Intensive Care, and Department of Medical and Health Sciences, Linköping University, Linköping, Sweden 
1 Conflict of interest: The authors have no conflicts of interest to disclose .

2 Clinical Trial registration number: NCT03325049

3

\section{$4 \quad$ References}

5 Ahlberg, M., Bäckman, C., Jones, C., Wahlter, S., Hollman Frisman, G., 2015. Moving on in 6 life after intensive care - partners' experience of group communication. Nurs. Crit. Care. 20 7 (5), 256-263.

8

9 Alderfer, MA., Fiese, BH., Gold, JI., Cutuli, JJ., Holmbeck, GN., Goldbeck, L., Chambers, CT., Abad, M., Spetter, D., Patterson, J., 2008. Evidence-based assessment in pediatric psychology: family measures. J Pediatr Psychol. 33(9):1046-61; discussion 1062-4.

Andersen T., 2003. Reflekterande processer. Samtal och samtal om samtalen. Stockholm: Mareld.

Antonovsky, A., Sourani, T., 1988. Family sense of coherence and family adaption. Journal of Marriage and the Family. 50:79-92.

Benzein, E., Berg, A., 2003. The Swedish version of Herth Hope Index--an instrument for palliative care. Scand J Caring Sci, 17(4), 409-415.

Benzein, E., Hagberg M., Saveman BI., 2008. 'Being appropriately unusual': a challenge for nurses in health-promoting conversations with families. Nursing Inquiry. 15 (2), 106-115. 
1 Benzein, E., Saveman, BI., 2008. Health-promoting conversations about hope and suffering

2 with couples in palliative care. Int J Palliat Nurs. 14 (9), 439-445.

4 Benzein, E., Olin, C., Persson, C., 2015. 'You put it all together' - families' evaluation of 5 participating in Family Health Conversations. Scand J Caring Sci. 29 (1), 136-44. doi:

$6 \quad 10.1111 /$ scs.12141.

7

8 Bylund, A., Årestedt, K., Benzein, E., Thorell, A., Persson C., 2016. Assessment of family

9 functioning: evaluation of the General Functioning Scale in a Swedish Bariatric Sample.

10 Scand J Caring Sci. 30 (3), 614-22. doi: 10.1111/scs.12269.

11

Charlson, ME., Pompei, P., Ales, K., MacKenzie, CR.., 1987. A new method of classifying prognostic comorbidity in longitudinal studies: development and validation. J Chronic Dis. 40:373-83.

15

Chiang VCL, Lee RLP, Ho FM, Leung CK, Tang YP, Wong WS, Ho YS, Tung YW, Lai HL.

Fulfilling the psychological and information need of the family members of critically ill patients using interactive mobile technology: A randomised controlled trial. Intensive Crit Care Nurs. 2017 Aug;41:77-83. doi: 10.1016/j.iccn.2017.03.006.

20

Davydow, DS; Gifford, JM., Desai, SV., Needham, DM., Bienvenu, OJ., 2008. Posttraumatic stress disorder in general intensive care unit survivors: a systematic review. Gen Hosp Psychiatry. 30(5):421-34. doi: 10.1016/j.genhosppsych.2008.05.006. 
1 Dorell, Å., Isaksson, U., Östlund, U., Sundin, K., 2017. Family Health Conversations have

2 Positive Outcomes on Families - A Mixed Method Research Study. Open Nurs J. 11:14-25. doi: 10.2174/1874434601711010014.

4

5 Dowdy, DW., Eid, MP., Sedrakyan, A., Mendez-Tellez, PA., Pronovost, PJ., Herridge, MS.,

6 Needham, DM., 2005. Quality of life in adult survivors of critical illness: a systematic review

7 of the literature. Intensive Care Med. 2005 May;31(5):611-20.

8

9 Dufault, K., Martocchio, BC., 1985. Hope: its spheres and dimensions. Nursing Clinics of 10 North America, 20(2), 379-391.

Eggenberger, SK., Nelms, TP., 2007. Being family: the family experience when an adult member is hospitalized with a critical illness. J Clin Nurs. 16(9):1618-28. Nurs. 25 (3-4):392-402. doi: 10.1111/jocn.13059.

Eriksson M \& Lindström B. (2005) Validity of Antonovsky's Sense of Coherence Scale - a systematic review. Journal of Epidemiology \& Community Health, 59:460-466

Everson, SA., Kaplan, GA., Goldberg, DE., et al., 2000. Hypertension incidence is predicted by high levels of hopelessness in Finnish men. Hypertension. 35:561-567.

Frivold, G., Slettebø, Å., Dale, B., 2016. Family members' lived experiences of everyday life after intensive care treatment of a loved one: a phenomenological hermeneutical study. J Clin 
1 Fumis, RR., Ranzani, OT., Martins, PS., Schettino, G., 2015. Emotional disorders in pairs of

2 patients and their family members during and after ICU stay. PLoS One. 23;10(1):e0115332.

3 doi: 10.1371/journal.pone.0115332.

4 Garvin, P., Nilsson, L., Carstensen, J., et al. 2009. Plasma levels of matrix metalloproteinase-

59 are independently associated with psychosocial factors in a middle-aged normal population.

$6 \quad$ Psychosom Med. 71:292-300.

7

8 Herth K., 1992. Abbreviated instrument to measure hope: development and psychometric 9 evaluation. Journal of Advanced Nursing, 17(10), 1251-1259.

10

Jensen, JF., Thomsen, T., Overgaard, D., Bestle, MH., Christensen, D., Egerod, I., 2015. Impact of follow-up consultations for ICU survivors on post-ICU syndrome: a systematic review and meta-analysis. Intensive Care Med. 41(5):763-75. doi: 10.1007/s00134-015-36891. Review.

Kirshbaum-Moriah D, Harel C, Benbenishty J. Family members' experience of intensive care unit support group: qualitative analysis of intervention. Nurs Crit Care. 2016 Dec 22. doi: 10.1111/nicc.12272.

Koulouras V, Konstanti Z, Lepida D, Papathanakos G, Gouva M. Shame feeling in the Intensive Care Unit patient's family members. Intensive Crit Care Nurs. 2017 Aug;41:84-89. doi: 10.1016/j.iccn.2017.03.011.

Köse, I., Zincircioğlu, Ç., Öztürk, YK., Çakmak, M., Güldoğan, EA., Demir, HF., Şenoglu, N., Erbay, RH., Gonullu, M., 2016. Factors Affecting Anxiety and Depression Symptoms in 
1 Relatives of Intensive Care Unit Patients. J Intensive Care Med. 31(9):611-7. doi:

$2 \quad 10.1177 / 0885066615595791$.

3 Orwelius, L., Kristenson, M., Fredrikson, M., Walther, S., Sjöberg, F., 2017. Hopelessness:

4 Independent associations with health-related quality of life and short-term mortality after

5 critical illness: A prospective, multicentre trial. Journal of Critical Care.41, 58-63.

6

7 Mitchell ML, Coyer F, Kean S, Stone R, Murfield J, Dwan T. Patient, family-centred care

8 interventions within the adult ICU setting: An integrative review. Aust Crit Care. 2016

9 Nov;29(4):179-193. doi: 10.1016/j.aucc.2016.08.002. Epub 2016 Sep 1. Review.

10

Maturana H., 1988. Reality: the search for objectivity or the quest for a compelling argument. The Irish Journal of Psychology. 9, 25-83.

Parker, AM., Sricharoenchai, T., Raparla, S., Schneck, KW., Bienvenu, OJ., Needham, DM., 2015. Posttraumatic stress disorder in critical illness survivors: a metaanalysis. Crit Care Med. 43(5):1121-9. doi: 10.1097/CCM.0000000000000882.

Probst, DR., Gustin, JL., Goodman, LF., Lorenz A Wells-Di Gregorio, SM., 2016. ICU versus Non-ICU Hospital Death: Family Member Complicated Grief, Posttraumatic Stress, and Depressive Symptoms. J Palliat Med. 19(4):387-93. doi: 10.1089/jpm.2015.0120.

Ridenour, AT., Daley, JG., Reich, W., 1999. Factor analyses of the family assessment device. Fam Process 38: 497-510. 
1 Sagy, S1., Dotan, N., 2001. Coping resources of maltreated children in the family: a

2 salutogenic approach. Child Abuse Negl. 25(11):1463-80.

3 Svenningsen H., Langhorn, L., Ågård, AS., Dreyer, P., 2017. Post-ICU symptoms,

4 consequences, and follow-up: an integrative review. Nurs Crit Care. 22(4):212-220. doi:

$5 \quad$ 10.1111/nicc.12165.

6

7 Tilburgs, B., Nijkamp, MD., Bakker, EC., van der Hoeven, H., 2015. The influence of social support on patients'quality of life after an intensive care unit discharge: A cross-sectional survey. Intensive Crit Care Nurs 31:336-342.

Ullman, AJ., Aitken, LM., Rattray, J., Kenardy, J., Le Brocque, R., MacGillivray, S., Hull, AM., 2015. Intensive care diaries to promote recovery for patients and families after critical illness: A Cochrane Systematic Review. Int J Nurs Stud. 52(7):1243-53. doi:

10.1016/j.ijnurstu.2015.03.020. Review.

van Beusekom, I., Bakhshi-Raiez, F., de Keizer, NF., Dongelmans, DA., van der Schaaf, M., 2016. Reported burden on informal caregivers of ICU survivors: a literature review. Crit Care. 21;20(1):16. doi: 10.1186/s13054-016-1185-9.

Ware, JE, Jr., Sherbourne, CD., 1992. The MOS 36-item short-form health survey (SF-36). I. Conceptual framework and item selection. Med Care, 30, 473-83.

Ware, JE., 1993. SF-36 health survey manual and interpretation guide., Boston., The New Health Institute, New England Medical Center. 
1 Ware, J., Kosinski, M., Dewey, J., 2001. How to score version 2 of the SF-36 health survey.

2 In.Rhode Island, USA: Quality Metric Incorporated; Lincoln.

3 WMA, The World Medical Association., 2013. Declaration of Helsinki - Etical Principals for

4 Medical Research Involving Human Subjects,

5 https://www.wma.net/policies-post/wma-declaration-of-helsinki-ethical-principles-for-

6 medical-research-involving-human-subjects/

7

8 Wright, LM., Leahey, M., 2009. Nurses and families: A guide to family assessment and 9 intervention (5 Rev ed ed.). Pennsylvania: F.A. Davis Company.

10

11 Wright, LM., Leahey, M., 2013. Nurses and families: A guide to family assessment and intervention (6th ed.). Philadelphia, PA: F.A. Davis.

13

Wåhlin, I., Ek, AC., Idvall, E., 2006. Patient empowerment in intensive care--an interview study. Intensive Crit Care Nurs. 22(6):370-7.

16

17 Ågård, AS., Egerod, I., Tønnesen, E., Lomborg, K., 2015. From spouse to caregiver and back: a grounded theory study of post-intensive care unit spousal caregiving. J Adv Nurs. 71(8):1892-903. doi: 10.1111/jan.12657. 
Figure 1. A flowchart showing the family member participants throughout the clinical study.

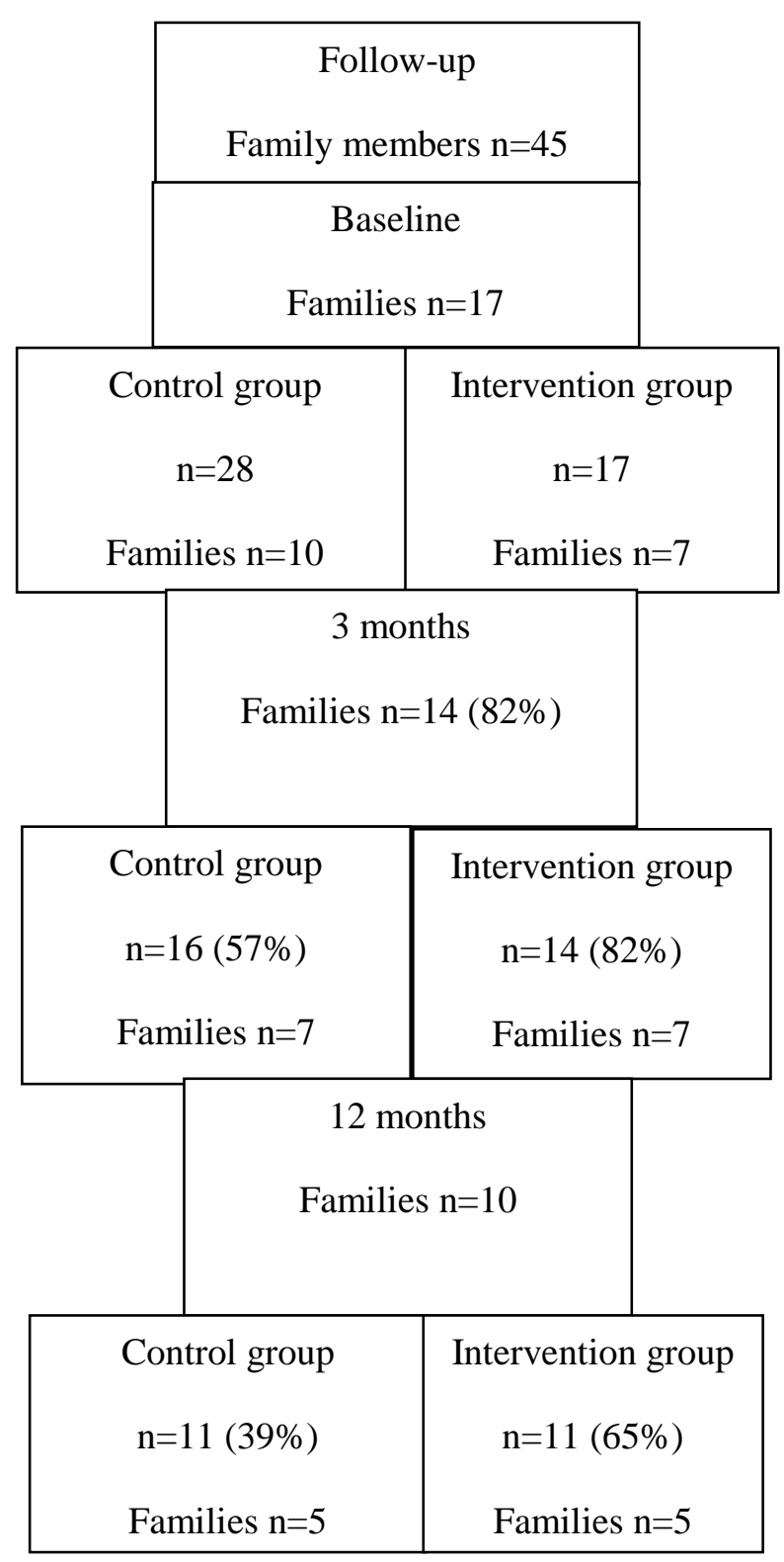


Figure 2. Mean changes in General Functioning/Family Functioning (GF), Sense of Coherence/Stress (SOC/KASAM), Physical Health Score (PCS), Mental Health Score (MCS), and Herth Hope Scale (HHI) scores over time in the control and intervention groups. The number of individuals at each time point for each group is shown in Figure 1.
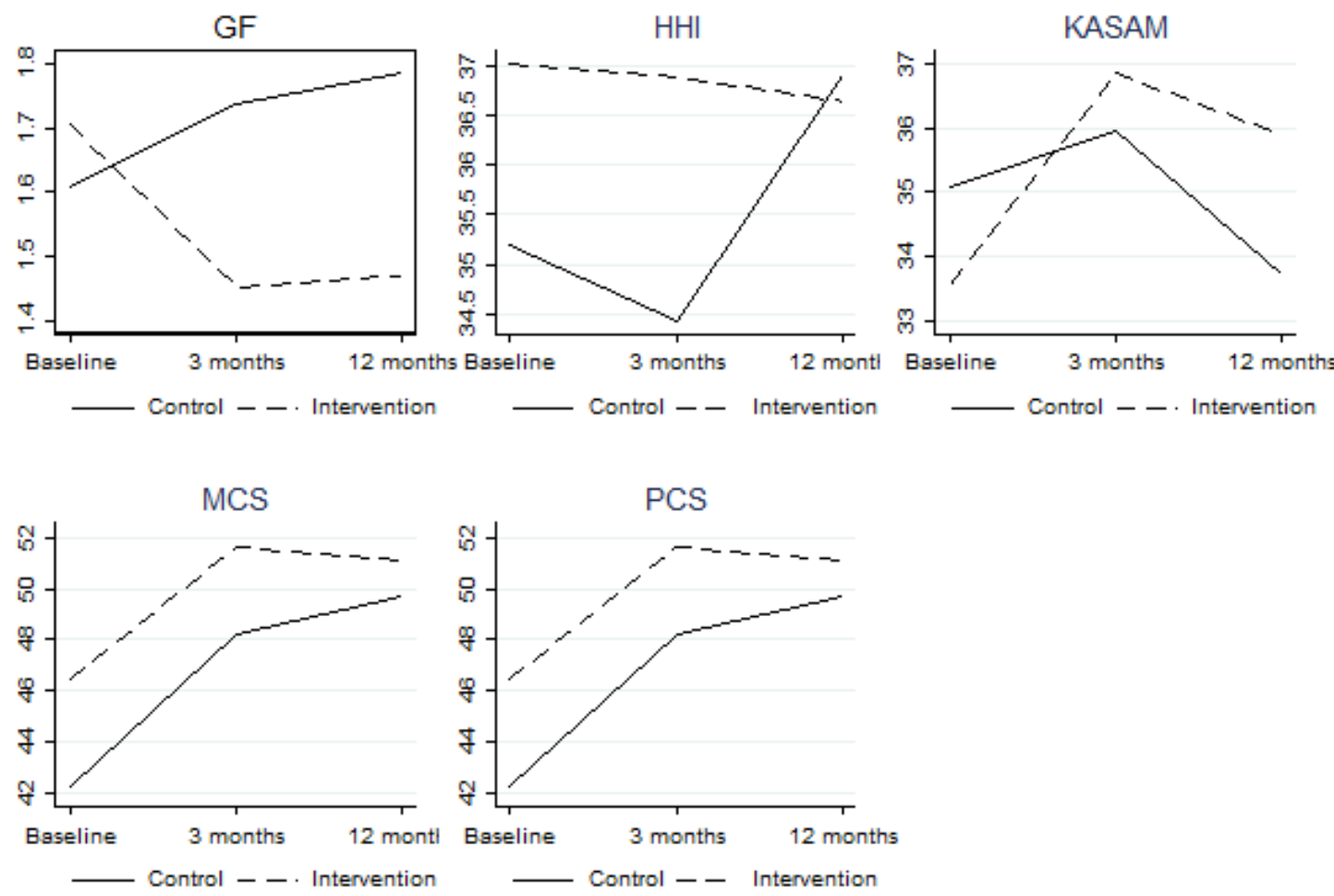
Table 1 Sociodemographic and clinical characteristics of the 10 families (28 individuals) in the control group and the 7 families (17 individuals) in the intervention group for the Health Promoting Conversations intervention. There were a total of 45 participants.

BMI

Type of co-morbidity (\%) risk

12-month mortality/10-year survival

Myocardial infarction

Hypertension

6

Diabetes

6

Stroke

Lung disease

Education, N (\%)

Elementary school or less

10 (35.8)

3 (17.6)

High school

9 (32.1)

$6(35,4)$

University

8 (28.6)

Missing data

$1(0.5)$

\section{Employment (\%)}

Full time

12 (42.9)

ns

Pension/disability pension/sick leave

Missing data

\section{Lifestyle (\%)}


0 min-3 hours/week

$>3$ hours/week

Missing data
$14(56)$

$12(42.9)$

2 (1.1)
10 (58.8)

5 (29.4)

2 (11.8) 
Table 2. Comparison between the control and intervention groups from baseline to 12 months.

\begin{tabular}{|c|c|c|c|c|c|c|c|c|}
\hline & & \multicolumn{2}{|l|}{ Control } & \multirow[t]{2}{*}{$\begin{array}{l}p- \\
\text { value }^{a}\end{array}$} & \multicolumn{2}{|c|}{ Intervention } & \multirow[t]{2}{*}{$p$-value ${ }^{a}$} & \multirow[t]{2}{*}{$p$-value ${ }^{b}$} \\
\hline & & Mean(SD) & No. & & Mean(SD) & No. & & \\
\hline \multirow[t]{3}{*}{$\mathrm{GF}$} & Baseline & $1.6(0.4)$ & 27 & & $1.7(0.6)$ & 17 & & 0.09 \\
\hline & 3 months & $1.7(0.5)$ & 16 & & $1.4(0.5)$ & 14 & & \\
\hline & 12 months & $1.8(0.5)$ & 11 & 0.33 & $1.5(0.6)$ & 11 & 0.03 & \\
\hline \multirow[t]{3}{*}{ KASAM } & Baseline & $35.1(9.3)$ & 27 & & $33.6(8.7)$ & 17 & & 0.01 \\
\hline & 3 months & $35.9(6.4)$ & 16 & & $36.8(10.2)$ & 14 & & \\
\hline & 12 months & $33.7(7.5)$ & 11 & 0.5 & $35.9(9.1)$ & 11 & 0.21 & \\
\hline \multirow[t]{3}{*}{$\mathrm{HHI}$} & Baseline & $35.2(4.2)$ & 27 & & $37.0(3.4)$ & 17 & & 0.23 \\
\hline & 3 months & $34.4(5.4)$ & 16 & & $36.8(4.1)$ & 14 & & \\
\hline & 12 months & $36.9(2.9)$ & 11 & 0.42 & $36.6(4.2)$ & 11 & 0.54 & \\
\hline \multirow[t]{3}{*}{$\mathrm{PF}$} & Baseline & $77.3(25.7)$ & 26 & & $67.9(32.7)$ & 17 & & 0.75 \\
\hline & 3 months & 79.3(29.1) & 16 & & $73.2(25.2)$ & 14 & & \\
\hline & 12 months & 77.3(30.1) & 11 & 0.06 & $77.3(21.8)$ & 11 & 0.34 & \\
\hline \multirow[t]{3}{*}{$\mathrm{RP}$} & Baseline & $66.3(46.3)$ & 26 & & $45.6(44.4)$ & 17 & & 0.24 \\
\hline & 3 months & 73.4(41.3) & 16 & & $55.3(46.2)$ & 14 & & \\
\hline & 12 months & $70.4(40.0)$ & 11 & 0.49 & $63.6(43.8)$ & 11 & 0.67 & \\
\hline \multirow[t]{3}{*}{$\mathrm{BP}$} & Baseline & $78.4(24.2)$ & 26 & & $58.0(27.2)$ & 17 & & 0.02 \\
\hline & 3 months & 81.2(17.4) & 16 & & $64.5(29.6)$ & 14 & & \\
\hline & 12 months & $78.7(22.4)$ & 11 & 0.65 & $70.7(22.1)$ & 11 & 0.3 & \\
\hline \multirow[t]{3}{*}{$\mathrm{GH}$} & Baseline & $61.5(22.8)$ & 26 & & $61.9(20.9)$ & 17 & & 0.47 \\
\hline & 3 months & 69.1(22.7) & 16 & & $66.9(21.6)$ & 14 & & \\
\hline & 12 months & $70.1(19.8)$ & 11 & 0.24 & $68.0(23.0)$ & 11 & 0.51 & \\
\hline \multirow[t]{3}{*}{ VT } & Baseline & $52.7(24.7)$ & 26 & & $57.0(24.4)$ & 17 & & 0.46 \\
\hline & 3 months & 64.7(23.6) & 16 & & $65.7(22.2)$ & 14 & & \\
\hline & 12 months & 64.1(18.3) & 11 & 0.12 & $63.6(22.4)$ & 11 & 0.22 & \\
\hline \multirow[t]{3}{*}{ SF } & Baseline & 73.1(28.6) & 26 & & $61.8(30.8)$ & 17 & & 0.01 \\
\hline & 3 months & $85.2(20.5)$ & 16 & & $81.2(27.2)$ & 14 & & \\
\hline & 12 months & $84.1(25.1)$ & 11 & 0.22 & $82.9(16.1)$ & 11 & 0.02 & \\
\hline \multirow[t]{3}{*}{$\mathrm{RE}$} & Baseline & $61.5(47.8)$ & 26 & & $64.7(39.9)$ & 17 & & 0.11 \\
\hline & 3 months & 75.0(41.3) & 16 & & $76.2(33.1)$ & 14 & & \\
\hline & 12 months & $87.9(30.8)$ & 11 & 0.4 & $75.8(36.8)$ & 11 & 0.65 & \\
\hline \multirow[t]{3}{*}{$\mathrm{MH}$} & Baseline & 72.0(19.4) & 26 & & $75.3(15.2)$ & 17 & & 0.09 \\
\hline & 3 months & 79.0(17.4) & 16 & & $85.1(11.1)$ & 14 & & \\
\hline & 12 months & $76.4(15.6)$ & 11 & 0.54 & $87.3(12.6)$ & 11 & 0.01 & \\
\hline \multirow[t]{2}{*}{ PCS } & Baseline & $47.2(12.0)$ & 26 & & $39.8(13.0)$ & 16 & & 0.54 \\
\hline & 3 months & $48.0(10.8)$ & 16 & & $41.6(14.7)$ & 14 & & \\
\hline
\end{tabular}




\begin{tabular}{|l|l|l|r|l|l|r|r|r|}
\hline & 12 months & $46.5(10.6)$ & 11 & 0.44 & $44.0(8.1)$ & 11 & 0.78 & \\
\hline MCS & Baseline & $42.2(12.7)$ & 26 & & $46.5(10.8)$ & 16 & & $\mathbf{0 . 0 4}$ \\
\hline & 3 months & $48.2(10.5)$ & 16 & & $51.6(9.1)$ & 14 & & \\
\hline & 12 months & $49.7(6.7)$ & 11 & 0.3 & $51.1(11.0)$ & 11 & 0.26 & \\
\hline
\end{tabular}

a $p$-value for comparison within group over time, from ANOVA for repeated measures.

${ }^{b} \mathrm{p}$-value for comparison between groups, mean over time, from ANOVA for repeated measures.

$\mathrm{GF}=$ Family function, KASAM=Stress measurement, $\mathrm{HHI}=$ Hope measurement, $\mathrm{PF}=$ physical functioning, $\mathrm{RP}=$ role functioning, $\mathrm{BP}=$ bodily pain, $\mathrm{GH}=$ general health, $\mathrm{VT}=$ =vitality, $\mathrm{SF}=$ Social functioning, $\mathrm{RE}=$ role emotional, $\mathrm{MH}=$ mental health, $\mathrm{PCS}=$ physical component score, $\mathrm{MCS}=$ mental component score 
Appendix 1. Mixed regression analysis of scores in the control and intervention groups from baseline up to 12 months after the intervention showing clusters of families.

\begin{tabular}{|c|c|c|c|}
\hline & $\begin{array}{l}\text { Mean change vs. } \\
\text { reference }\end{array}$ & p-value & $\begin{array}{l}95 \% \text { confidence } \\
\text { interval }\end{array}$ \\
\hline $\begin{array}{l}\text { GF 3m vs. baseline } \\
\text { Control } \\
\text { Intervention }\end{array}$ & $\begin{array}{l}0.19 \\
-0.36\end{array}$ & $\begin{array}{l}\text { reference } \\
\mathbf{0 . 0 0 5}\end{array}$ & $\begin{array}{l}0.01-0.36 \\
-0.61--0.11\end{array}$ \\
\hline $\begin{array}{l}\text { GF } 12 \mathrm{~m} \text { vs. baseline } \\
\text { Control } \\
\text { Intervention }\end{array}$ & $\begin{array}{l}0.08 \\
-0.22\end{array}$ & $\begin{array}{l}\text { reference } \\
0.67\end{array}$ & $\begin{array}{l}-0.31-0.46 \\
-0.27-0.42\end{array}$ \\
\hline $\begin{array}{l}\text { HHI 3m vs. baseline } \\
\text { Control } \\
\text { Intervention }\end{array}$ & $\begin{array}{l}-4.78 \\
4.06\end{array}$ & $\begin{array}{l}\text { reference } \\
0.06\end{array}$ & $\begin{array}{l}-7.56--1.99 \\
-0.14-8.27\end{array}$ \\
\hline $\begin{array}{l}\text { HHI } 12 \mathrm{~m} \text { vs. baseline } \\
\text { Control } \\
\text { Intervention }\end{array}$ & $\begin{array}{l}-0.09 \\
0.54\end{array}$ & $\begin{array}{l}\text { reference } \\
0.64\end{array}$ & $\begin{array}{l}-1.67-1.48 \\
-1.69-2.77\end{array}$ \\
\hline $\begin{array}{l}\text { KASAM 3m vs. baseline } \\
\text { Control } \\
\text { Intervention }\end{array}$ & $\begin{array}{l}-1.81 \\
4.64\end{array}$ & $\begin{array}{l}\text { reference } \\
0.46\end{array}$ & $\begin{array}{l}-6.59-2.97 \\
-2.39-11.7\end{array}$ \\
\hline $\begin{array}{l}\text { KASAM } 12 \mathrm{~m} \text { vs. baseline } \\
\text { Control } \\
\text { Intervention }\end{array}$ & $\begin{array}{l}-0.83 \\
2.38\end{array}$ & $\begin{array}{l}\text { reference } \\
0.45\end{array}$ & $\begin{array}{l}-5.16-3.49 \\
-3.74-8.50\end{array}$ \\
\hline
\end{tabular}




\begin{tabular}{|c|c|c|c|}
\hline $\begin{array}{l}\text { PCS 3m vs. baseline } \\
\text { Control } \\
\text { Intervention }\end{array}$ & $\begin{array}{l}1.93 \\
-2.10\end{array}$ & $\begin{array}{l}\text { reference } \\
0.59\end{array}$ & $\begin{array}{l}-3.21-7.07 \\
-9.75-5.55\end{array}$ \\
\hline $\begin{array}{l}\text { PCS } 12 \mathrm{~m} \text { vs. baseline } \\
\text { Control } \\
\text { Intervention }\end{array}$ & $\begin{array}{l}0.27 \\
1.98\end{array}$ & $\begin{array}{l}\text { reference } \\
0.63\end{array}$ & $\begin{array}{l}-5.23-5.78 \\
-5.99-9.95\end{array}$ \\
\hline $\begin{array}{l}\text { MCS 3m vs. baseline } \\
\text { Control } \\
\text { Intervention }\end{array}$ & $\begin{array}{l}2.96 \\
1.29\end{array}$ & $\begin{array}{l}\text { reference } \\
0.69\end{array}$ & $\begin{array}{l}-1.34-7.28 \\
-5.15-7.73\end{array}$ \\
\hline $\begin{array}{l}\text { MCS } 12 \mathrm{~m} \text { vs. baseline } \\
\text { Control } \\
\text { Intervention }\end{array}$ & $\begin{array}{l}3.50 \\
1.68\end{array}$ & $\begin{array}{l}\text { reference } \\
0.76\end{array}$ & $\begin{array}{l}-4.07-11.1 \\
-9.30-12.7\end{array}$ \\
\hline $\begin{array}{l}\text { PF 3m vs. baseline } \\
\text { Control } \\
\text { Intervention }\end{array}$ & $\begin{array}{l}7.18 \\
-4.61\end{array}$ & $\begin{array}{l}\text { reference } \\
0.53\end{array}$ & $\begin{array}{l}-2.52-16.9 \\
-18.8-9.59\end{array}$ \\
\hline $\begin{array}{l}\text { PF 12m vs. baseline } \\
\text { Control } \\
\text { Intervention }\end{array}$ & $\begin{array}{l}5.91 \\
2.83\end{array}$ & $\begin{array}{l}\text { reference } \\
0.69\end{array}$ & $\begin{array}{l}-3.96-15.8 \\
-11.1-16.8\end{array}$ \\
\hline $\begin{array}{l}\text { RP 3m vs. baseline } \\
\text { Control } \\
\text { Intervention }\end{array}$ & $\begin{array}{l}7.81 \\
-0.67\end{array}$ & $\begin{array}{l}\text { reference } \\
0.96\end{array}$ & $\begin{array}{l}-12.4-27.8 \\
-29.9-28.5\end{array}$ \\
\hline $\begin{array}{l}\text { RP } 12 \mathrm{~m} \text { vs. baseline } \\
\text { Control } \\
\text { Intervention }\end{array}$ & $\begin{array}{l}0.64 \\
18.1\end{array}$ & $\begin{array}{l}\text { reference } \\
0.50\end{array}$ & $\begin{array}{l}-36.6-37.9 \\
-34.6-70.7\end{array}$ \\
\hline
\end{tabular}




\begin{tabular}{|c|c|c|c|}
\hline $\begin{array}{l}\text { BP 3m vs. baseline } \\
\text { Control } \\
\text { Intervention }\end{array}$ & $\begin{array}{l}-0.69 \\
6.33\end{array}$ & $\begin{array}{l}\text { reference } \\
0.48\end{array}$ & $\begin{array}{l}-12.8-11.4 \\
-11.3-24.0\end{array}$ \\
\hline $\begin{array}{l}\text { BP } 12 \mathrm{~m} \text { vs. baseline } \\
\text { Control } \\
\text { Intervention }\end{array}$ & $\begin{array}{l}-6.27 \\
20.5\end{array}$ & $\begin{array}{l}\text { reference } \\
\mathbf{0 . 0 3}\end{array}$ & $\begin{array}{l}-19.4-6.83 \\
2.01-39.1\end{array}$ \\
\hline $\begin{array}{l}\text { GH 3m vs. baseline } \\
\text { Control } \\
\text { Intervention }\end{array}$ & $\begin{array}{l}3.83 \\
1.22\end{array}$ & $\begin{array}{l}\text { reference } \\
0.83\end{array}$ & $\begin{array}{l}-3.89-11.6 \\
-10.1-12.5\end{array}$ \\
\hline $\begin{array}{l}\text { GH } 12 \mathrm{~m} \text { vs. baseline } \\
\text { Control } \\
\text { Intervention }\end{array}$ & $\begin{array}{l}5.80 \\
-1.55\end{array}$ & $\begin{array}{l}\text { reference } \\
0.85\end{array}$ & $\begin{array}{l}-5.83-17.4 \\
-18.0-14.9\end{array}$ \\
\hline $\begin{array}{l}\text { VT 3m vs. baseline } \\
\text { Control } \\
\text { Intervention }\end{array}$ & $\begin{array}{l}8.75 \\
0.89\end{array}$ & $\begin{array}{l}\text { reference } \\
0.91\end{array}$ & $\begin{array}{l}-1.52-19.0 \\
-14.1-15.9\end{array}$ \\
\hline $\begin{array}{l}\text { VT } 12 \mathrm{~m} \text { vs. baseline } \\
\text { Control } \\
\text { Intervention }\end{array}$ & $\begin{array}{l}5.46 \\
5.27\end{array}$ & $\begin{array}{l}\text { reference } \\
0.60\end{array}$ & $\begin{array}{l}-8.66-19.6 \\
-14.7-25.2\end{array}$ \\
\hline $\begin{array}{l}\text { SF 3m vs. baseline } \\
\text { Control } \\
\text { Intervention }\end{array}$ & $\begin{array}{l}10.7 \\
5.82\end{array}$ & $\begin{array}{l}\text { reference } \\
0.60\end{array}$ & $\begin{array}{l}-4.23-25.6 \\
-16.1-27.7\end{array}$ \\
\hline $\begin{array}{l}\text { SF } 12 \mathrm{~m} \text { vs. baseline } \\
\text { Control }\end{array}$ & $\begin{array}{l}5.53 \\
19.4\end{array}$ & $\begin{array}{l}\text { reference } \\
0.29\end{array}$ & $\begin{array}{l}-16.2-30.7 \\
-16.2-55.0\end{array}$ \\
\hline
\end{tabular}




\begin{tabular}{|l|l|l|l|}
\hline Intervention & & & \\
\hline RE 3m vs. baseline & 6.14 & reference & $-9.14-21.4$ \\
Control & 0.62 & 0.96 & $-21.8-23.0$ \\
\hline Intervention & 14.4 & reference & $-26.0-54.9$ \\
Control $12 m$ vs. baseline & 1.31 & 0.96 & $-55.9-58.5$ \\
Intervention & 3.25 & reference & $-3.56-10.1$ \\
\hline MH 3m vs. baseline & 6.18 & 0.22 & $-3.78-16.1$ \\
Control & 1.44 & reference & $-7.34-10.2$ \\
Intervention & 1.6 & 0.07 & $-0.78-24.1$ \\
\hline MH 12m vs. baseline & & & \\
Control & Intervention & & \\
\hline
\end{tabular}

GF=Family function, $\mathrm{HHI}=$ Hope measurement, KASAM=Stress measurement, $\mathrm{PCS}=$ physical component score, $\mathrm{MCS}=$ mental component score, $\mathrm{PF}=$ physical functioning, $\mathrm{RP}=$ role functioning, $\mathrm{BP}=$ bodily pain, $\mathrm{GH}=$ general health, $\mathrm{VT}=$ vitality, $\mathrm{SF}=$ Social functioning, $\mathrm{RE}=$ role emotional, $\mathrm{MH}=$ mental health, 
Appendix 2. General functioning/Family functioning (GF), Sense of Coherence/Stress (SOC/KASAM), Physical Health Score (PCS), Mental Health Score (MCS), and Herth Hope Scale (HHI) scores over time in patients and families in the control and intervention groups.
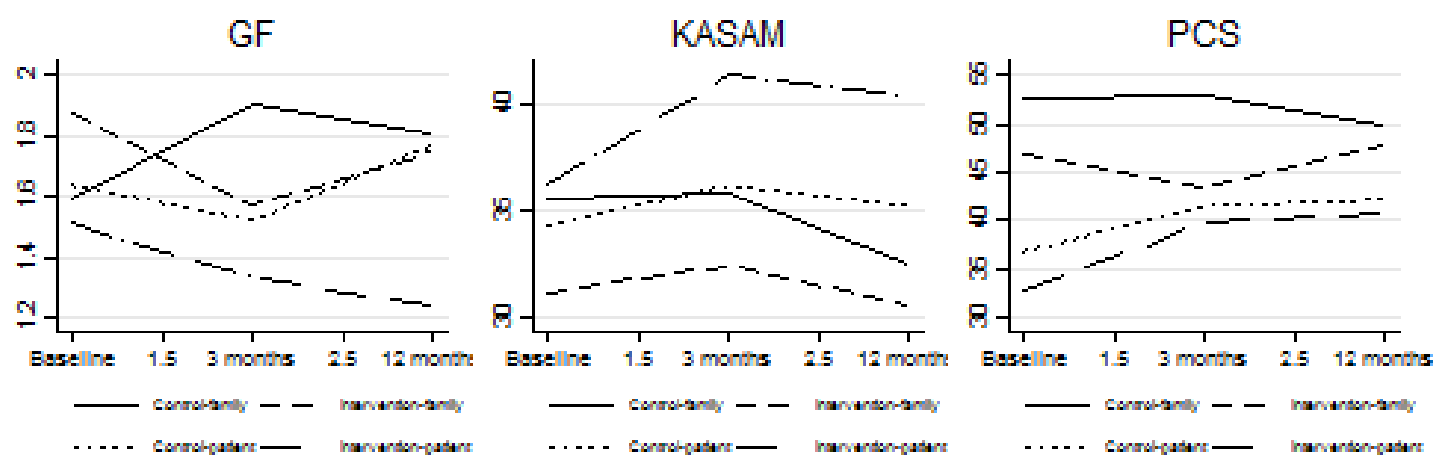

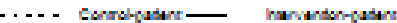
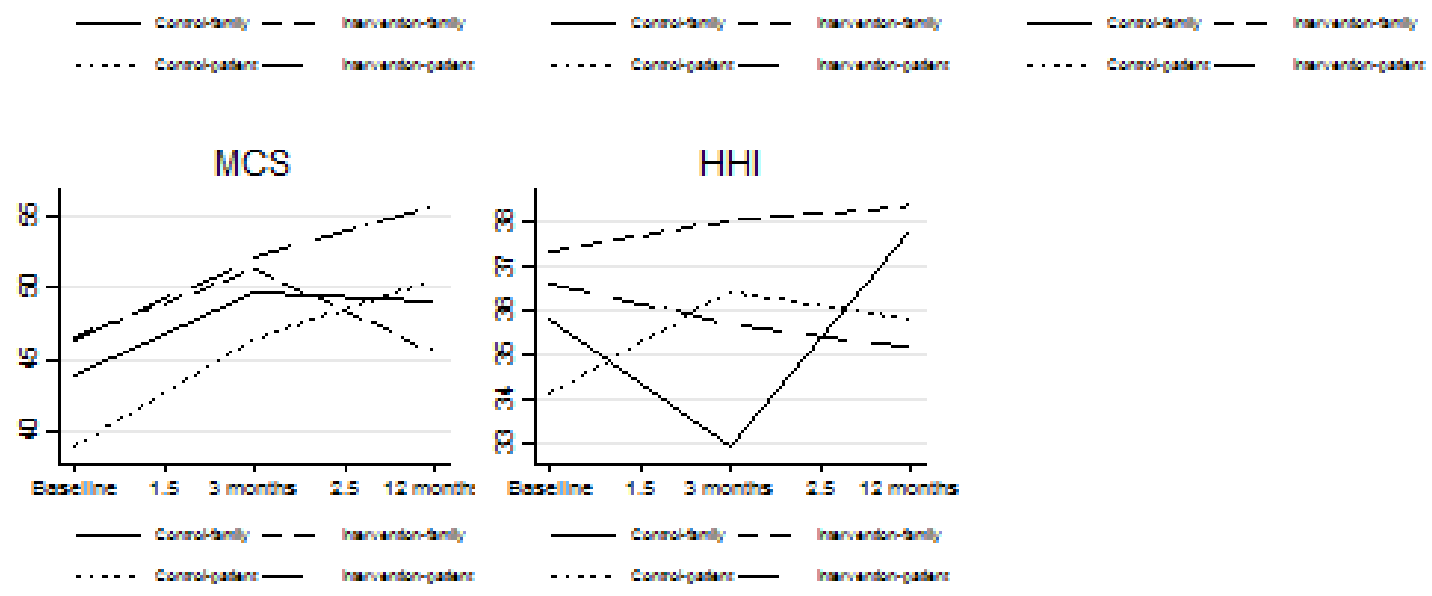